\title{
Reflexões sobre a prática docente e experiências de futuros professores em cursos de língua online do FIVU (Formação em Idiomas para a Vida Universitária)
}

\author{
Maiara Afonso de Lima \\ Universidade Federal do Paraná \\ maiaraafonso@ufpr.br \\ Vinícius Peretti \\ Universidade Federal do Paraná \\ vinicius.peretti@ufpr.br \\ Fernanda Silva Veloso \\ Universidade Federal do Paraná \\ fernandaveloso@ufpr.br
}

RESUMO: Com o auto isolamento exigido pelo COVID-19, o ensino presencial, parte fundamental da experiência de estágio, se tornou inviável implicando e favorecendo o aparecimento de novos campos para a sua realização. Surge, assim, a oferta de cursos de línguas, ainda que temporária, para o ensino remoto emergencial (ERE), como, por exemplo, as aulas do FIVU. Este artigo tem como objetivo principal apresentar e discutir a elaboração e a aplicação de unidades temáticas de língua italiana elaboradas por dois alunos do curso de Letras Italiano, regularmente matriculados na disciplina de Prática de Ensino de Línguas Estrangeiras Modernas Neolatinas 1, além de apresentar sua experiência didática nas regências em sala de aula virtual. A unidade didática e as aulas virtuais foram viabilizadas por meio de compartilhamento de tela, apresentações de slides, bem como por aplicativos online, como o Mentimeter e o Learning Apps. Os cursos de extensão de Língua Italiana estão vinculados ao projeto de extensão FIVU (Formação em Idiomas para a Vida Universitária) e foram viabilizados por meio de uma parceria entre docente orientadora, alunos estagiários e Programa de PósGraduação em Educação (PPGE) da Universidade Federal do Paraná (UFPR). O curso de nível básico, e com duração de 30 horas, foi ministrado no Teams Office 365 institucional e teve uma carga horária semanal de 4 horas-aula. O público-alvo foram nove alunos de mestrado e doutorado do PPGE-UFPR, muitos deles já com conhecimento prévio da língua italiana devido às leituras de suas bibliografias de pesquisa.

Palavras-chave: Prática de ensino. Ensino remoto emergencial. Unidade didática. 
Reflexões sobre a prática docente e experiências de futuros professores em cursos de língua online do FIVU

(Formação em Idiomas para a Vida Universitária)

Maiara Afonso de Lima

Vinícius Peretti

Fernando Silva Veloso

\begin{abstract}
Con l'isolamento causato dal COVID-19, i lavori faccia a faccia sono diventati irrealizzabili, implicando e favorendo la comparsa di nuovi campi di stage adatti a questa nuova realtà. Nasce così la possibilità di offrire corsi di lingua, anche se temporanei, per la didattica a distanza di emergenza. I corsi di estensione della Lingua Italiana sono vincolati al progetto di estensione FIVU (Formação em Idiomas para a Vida Universitária) e sono stati resi possibili attraverso una partnership tra studenti, professoressa e Programa de Pós-Graduação em Educação (PPGE) dell'Universidade Federal do Paraná (UFPR). Il corso di livello principiante della durata di 30 ore è stato tenuto presso il Teams Office 365 istituzionale, ed ha avuto un carico di lavoro settimanale di 4 ore di lezione. Il pubblico di riferimento era di nove studenti di master e dottorato del PPGE-UFPR e molti di loro avevano già una conoscenza precedente della lingua italiana a causa delle letture delle loro bibliografie di ricerche. L'obiettivo principale di questo articolo è presentare e discutere lo sviluppo e l'applicazione delle unità didattiche elaborate da due studenti del corso di Lettere Italiano, iscritti alla disciplina di Prática de Ensino de Linguas Estrangeiras Modernas Neolatinas, oltre a presentare l'esperienza didattica degli studenti nell'insegnamento di italiano in una una classe virtuale. Le unità didattiche e le lezioni virtuali sono state fatte attraverso la condivisione dello schermo, presentazioni di diapositive, nonché attraverso applicazioni online, come Mentimeter e Learning Apps.
\end{abstract}

Parole-chiave: Pratica di insegnamento. Didattica a distanza di emergenza. Unità didattica.

ABSTRACT: With the self-isolation required by COVID-19, face-to-face teaching, a fundamental part of the internship experience, became unfeasible, implying and favoring the appearance of new fields for its realization. Thus, there came the offer of language courses, even though temporary, for emergency remote education (ERE), such as the FIVU classes. The main objective of this article is to present and discuss the development and application of thematic units of Italian language prepared by two students of the Italian Language course, regularly enrolled in the Teaching Practice of Neolatine Modern Foreign Languages, in addition to presenting their didactic experience in the regency in a virtual classroom. The didactic unit and virtual classes were made possible through screen sharing, slide shows, as well as through online tools, such as Mentimeter and Learning Apps. The Italian language extension courses are linked to the FIVU extension project (Training in Languages for University Life) and were made 
Reflexões sobre a prática docente e experiências de futuros professores em cursos de língua online do FIVU

(Formação em Idiomas para a Vida Universitária)

Maiara Afonso de Lima

Vinícius Peretti

Fernando Silva Veloso

possible through a partnership between the faculty advisor, the intern students, and the Graduate Program in Education (PPGE) of the Federal University of Paraná (UFPR). The basic level course, with a duration of 30 hours, was given through the institutional Teams Office 365 and had a weekly load of 4 class hours. The target audience was nine master's and doctoral students from PPGE-UFPR, many of whom already had prior knowledge of the Italian language owing to the readings of their research bibliographies.

Keywords: Teaching practice. Emergency remote education. Didactic unit.

\section{Introdução}

A pandemia causada pelo vírus da COVID-19 trouxe para o cotidiano universitário uma nova realidade: os períodos especiais e as aulas online. A retomada do calendário acadêmico de maneira virtual representou e continua representando um desafio, principalmente nas universidades públicas, que possuem diferenças sociais enormes entre seus estudantes, e precisaram encontrar uma maneira de atender a toda sua comunidade acadêmica. Mesmo que as discussões e os méritos dessa retomada sejam muito abrangentes, o fato é que, na UFPR, a solução encontrada para contornar minimamente a situação foi o estabelecimento dos períodos especiais emergenciais, possibilitando a oferta de algumas das disciplinas aos estudantes que possuem as devidas condições para cursá-las.

Com o objetivo de atender a pedidos e possibilitar aos estudantes de licenciatura em Letras da UFPR o cumprimento da carga horária da disciplina de Prática de Docência em LE Moderna 1: Espanhol/Francês/Italiano, surgiu a ideia da elaboração de cursos de língua estrangeira (LE) online. Dessa forma, os alunos da graduação poderiam exercer a prática de ensino da LE, seja do italiano, espanhol ou francês. Nesse momento excepcional, a disciplina de Prática teve sua estrutura 
Reflexões sobre a prática docente e experiências de futuros professores em cursos de língua online do FIVU

(Formação em Idiomas para a Vida Universitária)

Maiara Afonso de Lima

Vinícius Peretti

Fernando Silva Veloso

dividida em aulas teóricas e aulas práticas, que foram possibilitadas pela criação dos cursos já citados, dos quais o primeiro módulo do curso de "Italiano: temas da vida acadêmica" fez parte e sobre o qual esse artigo se desdobrará mais especificamente. O módulo 1 do curso "Italiano: temas da vida acadêmica" surgiu de uma parceria entre o programa FIVU (Formação de Idiomas para a Vida Universitária), a docente orientadora Profa. Dra. Fernanda S. Veloso, alunos praticantes, dos quais dois são também autores deste artigo, e do programa de PósGraduação em Educação (PPGE) da Universidade Federal do Paraná.

Como o PPGE-UFPR mantém relações diretas com universidades italianas, seja com programas de formação sanduíche, trabalhos remotos ou atividades de pesquisa como o CAPES PRINT ${ }^{1}$ e o Projeto ERASMUS UFPR-UNIPA/Itália ${ }^{2}$, entendeu-se que haveria a necessidade e o interesse dos alunos do programa em aprender, mesmo que basicamente, a língua italiana e os funcionamentos da vida universitária na Itália, para assim melhorar a interação com os parceiros italianos e usufruir amplamente das oportunidades oferecidas por tais parcerias.

\section{FIVU}

Antes de nos debruçarmos sobre as experiências didáticas, faz-se necessário conhecer o meio que as proporcionou. Sigla para "Formação de idiomas para vida universitária", o FIVU é um projeto de extensão da UFPR iniciado em 2009, destinado a ajudar na formação dos licenciandos em Letras no ensino de Línguas Estrangeiras Modernas. Dentre as línguas estrangeiras modernas entram o francês, o espanhol e o italiano, mas o projeto oferece também cursos de inglês, alemão e japonês. E, ao mesmo tempo que auxilia na formação dos alunos como docentes, o FIVU proporciona à comunidade universitária da UFPR, especificamente aos 
Reflexões sobre a prática docente e experiências de futuros professores em cursos de língua online do FIVU

(Formação em Idiomas para a Vida Universitária)

Maiara Afonso de Lima

Vinícius Peretti

Fernando Silva Veloso

alunos da graduação e pós-graduação, aulas gratuitas de LE para quem possui interesse em intercâmbio, mobilidade acadêmica ou atividades acadêmicas realizadas dentro da própria universidade.

Os cursos oferecidos pelo FIVU são voltados para usos discursivos em contextos acadêmicos, com práticas linguísticas orais e escritas informais, como diálogos e produção de textos descritivos e narrativos simples, e práticas que trabalham situações mais formais como a formulação de trabalhos acadêmicos e apresentação de seminários em LE. Assim, podemos classificar tais cursos como "LE com objetivos universitários/ para fins acadêmicos" como proposto por Picanço e Veloso (2019).

A seguir, apresentamos como está configurado, especificamente, o curso de língua italiana, na modalidade remota, dentro do FIVU.

\section{2. "Italiano: temas da vida acadêmica" um curso para fins específicos}

O primeiro módulo do curso foi oferecido em 15 encontros, com a duração de dois meses, e as aulas foram ministradas pela plataforma Teams office 365, que é a atual plataforma institucional da UFPR. Foram ao todo nove alunos do PPGE inscritos no curso, dos quais alguns já haviam tido contatos prévios e distintos com a língua italiana, formando então um grupo de estudantes heterogêneos e desnivelados em termos linguísticos.

O curso foi ministrado ao todo por quatro alunos docentes, que também possuíam diferentes níveis de experiência com o ensino de LE. As aulas foram distribuídas entre os alunos docentes de maneira que cada ministrante assumisse duas aulas por semana. Tal praticante era também responsável pela elaboração do material didático, pela regência das aulas e pela correção das atividades da semana 
Reflexões sobre a prática docente e experiências de futuros professores em cursos de língua online do FIVU

(Formação em Idiomas para a Vida Universitária)

Maiara Afonso de Lima

Vinícius Peretti

Fernando Silva Veloso

correspondente. Dessa forma, as aulas foram intercaladas e os professores ministraram mais de uma semana de aula cada. Além disso, todos os alunos assistiram e auxiliaram nas aulas dos colegas.

Como mencionado anteriormente, o objetivo do curso foi abordar temas que fossem relevantes aos alunos que utilizam ou poderiam vir a utilizar o italiano em suas experiências acadêmicas na pós-graduação, assim buscando desenvolver as habilidades linguísticas e apresentando aspectos culturais relevantes dentro desse público-alvo e dessa esfera de atuação. Olhando pelos objetivos bem delineados e específicos do curso, pode-se entender que o italiano foi trabalhado como LE para fins específicos, ou seja, como uma "microlíngua", nome pelo qual essa modalidade também é conhecida.

Segundo Ballarin (2007), a "microlíngua" é uma variedade da língua usada por especialistas, profissionais e/ou um grupo de pessoas de certos setores da sociedade com o objetivo de obter-se a maior clareza possível sobre as nuances específicas do conhecimento. Tal prática pode apresentar aspectos lexicais, fonológicos e até sintáticos próprios. Por exemplo, a "microlíngua" médica, que engloba termos, verbos e expressões para lidar com a anatomia humana, seus sistemas e suas dinâmicas. Termos como "cerebelo", "intravenoso" e "incisão", que não são usados, ou que são pouco usados fora do ambiente médico. Essa "microlíngua", ou língua para fim específico, portanto, é capaz também de identificar o indivíduo como membro de um determinado grupo social, no caso, o grupo dos médicos. Vale a pena diferenciar a ideia de língua para fins específico daquela de "jargão" (tradução livre pro termo "gergo" usado em italiano), diferença que fica bem clara no seguinte fragmento do texto Didattica delle microlingue de Elena Ballarin: 


\begin{abstract}
A fim de determinar mais claramente aquilo que se entende por microlíngua, é importante analisar o escopo de uso da língua. Dois médicos que, em uma reunião cotidiana, fazem piadas recorrendo à microlíngua da medicina apenas para não serem entendidos pelas outras pessoas, não estão usando a microlíngua, mas um jargão corporativo, ou seja, uma variedade de língua usada por certos grupos, não necessariamente de baixo estrato social, para se comunicar entre si sem serem compreendidos por não-falantes desse jargão. O escopo é de selecionar o destinatário, impedindo a compreensão dos nãomédicos. (BALLARIN, 2007) ${ }^{3}$
\end{abstract}

Vemos então que ao passo que o uso do "jargão" tem como objetivo excluir e delimitar os indivíduos pertencentes a um determinado meio, a língua para fins específicos é um movimento muito mais natural e prático das diferentes áreas de convivência e uso linguístico. Ela possui aspectos muito específicos que dificilmente são estudados e aprofundados em cursos de idiomas mais gerais. Logo, a criação e a procura de um curso de italiano voltado para o uso da língua nesse meio específico de vida universitária, será do interesse de um público-alvo muito mais restrito, da mesma forma o conteúdo abordado e as tarefas de fato relevantes para os alunos serão muito mais direcionadas e pensadas com esse fim bem delimitado.

Depois de entender o conceito e a função dos cursos de idiomas para fins específicos, torna-se mais fácil entender o porquê do curso "Italiano: temas da vida acadêmica" se enquadrar nessa modalidade. Assim, entende-se também a necessidade da criação de unidades didáticas bem delineadas e com temáticas mais específicas, atividades sempre voltadas para o mesmo objetivo e apresentação da língua italiana sempre pensada no uso que se faz do idioma dentro do meio universitário e suas eventuais particularidades.

Os temas que consideramos relevantes e que foram trabalhados durante as aulas são: apresentação pessoal, sistema universitário italiano, auxílios disponíveis 
Reflexões sobre a prática docente e experiências de futuros professores em cursos de língua online do FIVU

(Formação em Idiomas para a Vida Universitária)

Maiara Afonso de Lima

Vinícius Peretti

Fernando Silva Veloso

aos estudantes, ambientes, alimentação, mobilidade dentro e fora do campus, tempo livre na universidade, atividades extracurriculares, diferenças culturais e geográficas entre sul e norte italianos, as quais serão discutidas adiante.

\section{Unidades didáticas, elaboração e adaptações.}

Tendo em mente que os objetivos dos materiais didáticos e, portanto, das aulas, era ensinar sobre a vida acadêmica italiana, foram desenvolvidas ao todo 14 unidades temáticas durante o curso. Como as aulas seriam ministradas em ambiente virtual, toda sua proposta foi voltada para tal, ou seja, as atividades foram pensadas para que fossem viáveis cada um estando atrás de sua tela. Isso incluiu pequenos jogos, aplicativos e ferramentas digitais, e até mesmo um ritmo mais lento de aula devido ao atraso das falas presente nas comunicações via internet.

Das 14 unidades temáticas totais, apresentaremos neste artigo exemplos de apenas duas delas": uma intitulada como "A vida universitária italiana", que trata dos funcionamentos dos diferentes ambiente universitários, como as aulas, o restaurante universitário, o uso da carteirinha de estudantes, dentre outros assuntos; e outra intitulada "A mobilidade dentro e fora do campus", que visa apresentar e exemplificar os diferentes meios de locomoção usados pelos estudantes italianos em diferentes espaços da cidade.

Adotou-se, ao longo do curso, uma concepção pós-estruturalista da linguagem, que não vê a língua apenas como código linguístico a ser aprendido e decifrado pelo falante, mas como discurso, relativo a cada pessoa que a usa e ao ambiente em que vem sendo usada (JORDÃO, 2006). Língua e cultura estão ligadas nas suas formas mais básicas, sendo então impossível falar de uma sem falar ou usar a outra. 
Reflexões sobre a prática docente e experiências de futuros professores em cursos de língua online do FIVU

(Formação em Idiomas para a Vida Universitária)

Maiara Afonso de Lima

Vinícius Peretti

Fernando Silva Veloso

Além disso, como a linguagem é responsável por permitir que nossos entendimentos de mundo sejam construídos de uma maneira, e não de outra, o papel do professor que se vale dessa concepção de linguagem é o de apresentar aos alunos novas formas de interpretar e ler o mundo (JORDÃO, 2006).

Sabendo disso, os materiais apenas mencionados foram elaborados para que os alunos pudessem conceber e entender uma nova forma de experimentar o mundo, levando em conta não só a cultura italiana no geral, mas uma nova concepção da cultura universitária, que quando colocada em contraste com a brasileira, evidencia o comportamento e o uso linguístico esperados naquele ambiente.

Além disso, a preparação das unidades didáticas seguiu uma abordagem de ensino que não traz como foco a fixação das estruturas gramaticais da LE, mas a comunicação eficiente dos estudantes quando se arriscam na LE, usando a gramática apenas como apoio para sanar possíveis dúvidas dos alunos.

A estrutura das unidades didáticas seguiu o modelo apresentado por Jane Willis (1996), da organização de material baseado na abordagem por tarefas. Tal abordagem, segundo Xavier (2012), propõe foco no resultado e no desenvolvimento das habilidades comunicativas, e é aquela que, como o nome aponta, propõe no decorrer da aula tarefas que devem ser realizadas pelo aluno, oferecendo ao aprendiz uma ampla exposição à LE, estimulando-o a se desenvolver na língua alvo.

Voltando agora para o modelo de Willis (1996), vejamos as fases que ela propõe juntamente com os exemplos das unidades criadas no curso. Para Willis, a aula deve ser dividida em três etapas básicas: pré-tarefa, ciclo da tarefa e foco na linguagem. A "pré-tarefa” é a responsável por introduzir o tema da aula e despertar 
Reflexões sobre a prática docente e experiências de futuros professores em cursos de língua online do FIVU (Formação em Idiomas para a Vida Universitária)

Maiara Afonso de Lima

Vinícius Peretti

Fernando Silva Veloso

o interesse do aluno, o que pode ser feito por meio de imagens, vídeos, ou até mesmo colocando algumas questões sobre o tópico para instigar o envolvimento dos estudantes. Vale lembrar que a pré-tarefa serve de apoio e embasamento para a efetivação da tarefa.

O exemplo abaixo foi retirado da unidade "A mobilidade dentro e fora do campus" e mostra como a temática a ser trabalhada na aula vem introduzida de maneira mais global, por meio de perguntas mais gerais que guiam o aluno até o ponto de início do conteúdo mais específico a ser trabalhado:

1. Nel tuo tempo libero ti piace fare un giro? Dove tu vai?

2. E come fai TU quando devi andare all'università? Guarda le foto $e$ condividi quello o quelli mezzo(i) che prendi per andarci.

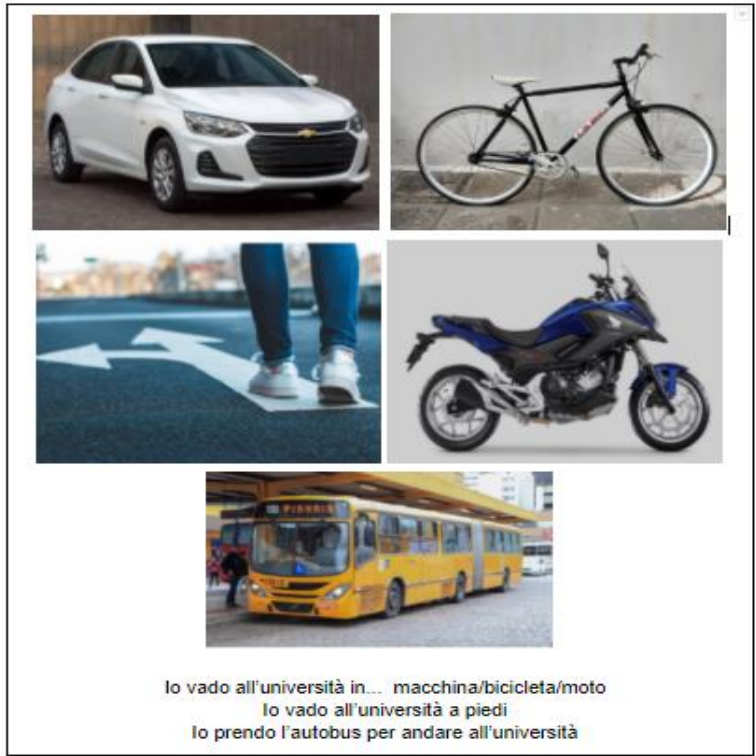

3. E se uno va in Italia, come farà per spostarsi? Secondo te, quali sono le possibilità?

Imagem 1: exemplo de pré-tarefa na UD A mobilidade dentro e fora do campus 
Reflexões sobre a prática docente e experiências de futuros professores em cursos de língua online do FIVU

(Formação em Idiomas para a Vida Universitária)

Maiara Afonso de Lima

Vinícius Peretti

Fernando Silva Veloso

Vemos que a primeira pergunta busca utilizar o conhecimento de mundo do estudante, podendo ser respondida apenas com seus conhecimentos prévios. Com isso, além de preparar o ambiente da aula, ela também valoriza o que o aluno já sabe. Da mesma forma, a segunda pergunta também usa das experiências do estudante, mas além de trazer recursos visuais, que facilitam o direcionamento do raciocínio do aluno, ela exige que o aprendiz tenha ou adquira um vocabulário mais específico dentro da LE. Pensando nisso, são colocadas também sugestões de como o aluno poderia formular sua resposta na LE usando esse léxico prédeterminado. Para finalizar a pré-tarefa, a terceira pergunta direciona o pensamento do aluno para o objetivo último da aula, ou seja, a locomoção urbana na Itália.

O momento de realizar a tarefa é chamado de "ciclo da tarefa", sempre com foco na comunicação e buscando a interação com a língua alvo. Vale lembrar que a tarefa necessita de um objetivo claro a ser alcançado pelo estudante. Na tarefa a seguir, retirada da unidade "A vida universitária italiana", por exemplo, o aluno precisa assistir ao vídeo para poder responder às perguntas e interagir com os colegas sobre o conteúdo proposto: 
Reflexões sobre a prática docente e experiências de futuros professores em cursos de língua online do FIVU (Formação em Idiomas para a Vida Universitária)

Maiara Afonso de Lima

Vinícius Peretti

Fernando Silva Veloso

4) Guarda il video Erasmus@UNIMORE per conoscere l'esperienza di alcuni studenti Erasmus presso l'università degli studi di Modena e Reggio Emilia.
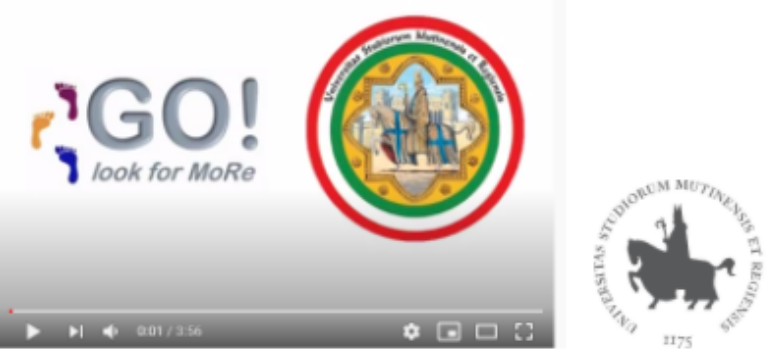

Tratto da: https://wnweyoutube comivatch? $v=u V k t a q$ Wok $1 \mathrm{k}$

a) Dopo aver guardato il video, quali informazioni sei riuscita/o a capire?

b) Sai spiegare il motivo per cui vuoi fare un interscambio?

\begin{tabular}{|l|l|}
\hline Informazioni personali & Perché fai linterscambio? \\
\hline $\begin{array}{l}\text { Io sono Ariana, una ragazza spagnola, di } \\
\text { Barcelona. Ho 24 anni e sto studiando } \\
\text { scienza della educazione. }\end{array}$ & $\begin{array}{l}\text { perché voglio imparare l'educazione di Loris } \\
\text { Malaguzzi. }\end{array}$ \\
\hline
\end{tabular}

c) Secondo te, tutti gli studenti del video sono stranieri?

Imagem 2: exemplo de tarefa da UD A vida universitária italiana

Deste modo, o aluno já sabe, antes mesmo de começar a assistir ao vídeo, que ele está fazendo isso com um propósito, o que já o leva a prestar mais atenção ao conteúdo exibido. Na tarefa, além de demonstrar que foi capaz de compreender um áudio na LE na primeira pergunta, o aluno precisa usar a língua alvo ativamente, produzindo oralmente sua resposta ao item $b$. Vemos também que, para auxiliar o aluno, um exemplo de como formular essa resposta foi retirado do próprio vídeo, o que traz direcionamento, mas não obriga a utilização de uma estrutura pré fixada. A última pergunta vem apenas para concluir a tarefa e chamar a atenção dos alunos para um aspecto fonológico do vídeo: os diferentes sotaques de falantes de italiano de diferentes nacionalidades. 
Reflexões sobre a prática docente e experiências de futuros professores em cursos de língua online do FIVU

(Formação em Idiomas para a Vida Universitária)

Maiara Afonso de Lima

Vinícius Peretti

Fernando Silva Veloso

Para concluir, a fase "foco na linguagem", também conhecida como póstarefa, é a etapa ideal para refletir sobre o resultado alcançado na tarefa, além de ser o melhor momento para abordar aspectos gramaticais e fazer supostas correções de uso da LE, guiando os alunos numa reflexão ativa e crítica sobre a LE. A seguir, vemos o exercício proposto como conclusão da tarefa exemplificada anteriormente:

d) Fai l'attività sul sito Learning apps e poi completa la tabella con gli aggettivi di nazionalità; Link dell'attività: https://learningapps.org/display?v=pryaagp7320

\begin{tabular}{|c|c|c|}
\hline Paese & Maschile & Femminile \\
\hline Italia & italiano & italiana \\
\hline Brasile & & \\
\hline Germania & & \\
\hline Olanda & & \\
\hline Francia & & \\
\hline Giappone & & \\
\hline
\end{tabular}

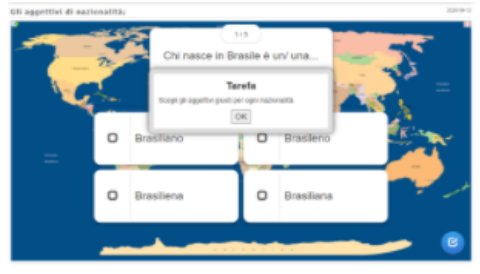

Le preposizioni a e in:

Abitare/ vivere $\mathrm{a}=$ città, piccolo paese.

Abitare/ vivere in = indirizzo, regione,

Paese, continente.

Imagem 3: exemplo de pós-tarefa da UD A vida universitária italiana

Depois de trabalhar com o vídeo e chamar a atenção dos alunos para as diferentes nacionalidades que aparecem falando italiano, voltamos o olhar do grupo para um aspecto mais formal na língua: os adjetivos de nacionalidade, usando de uma ferramenta online, que será apresentada na seção 4 deste trabalho, junto com um exercício mais tradicional de organizar os itens na tabela. Nesse momento, além de evidenciar a forma, os alunos podem sanar eventuais dúvidas sobre o que foi trabalhado até o momento. Além disso, foi adicionado também um espaço extra de evidência gramatical, abrindo espaço na aula para explicar e 
Reflexões sobre a prática docente e experiências de futuros professores em cursos de língua online do FIVU

(Formação em Idiomas para a Vida Universitária)

Maiara Afonso de Lima

Vinícius Peretti

Fernando Silva Veloso

exemplificar o uso das preposições $a$ e in, seguindo um gancho direto com a ideia de nacionalidade e de habitação, um dos fatores determinantes no uso dessas preposições.

Concluindo o desenvolvimento das unidades didáticas, vale pontuar que todos os textos utilizados em sala são materiais autênticos didatizados, ou seja, são documentos produzidos para uso comum da língua, e não artificialmente desenvolvidos para o ensino de LE, assim o aluno tem o contato mais próximo possível da realidade de uso da língua alvo.

\section{Experiência em sala de aula}

A disciplina de Prática de Docência em LE Moderna 1: Espanhol/Francês/Italiano, na modalidade remota, foi uma experiência no mínimo desafiadora, uma vez que era a primeira vez que estávamos ministrando aulas a distância, em tempos tão delicados como o atual. O desafio se deu tanto pela adaptação à plataforma Teams, nova se comparada com outras plataformas semelhantes presentes na internet como o Discord e o Google Meets, quanto pela nova dinâmica de interação professor-aluno, consideravelmente diferente da aula presencial, principalmente pela falta de contato visual.

Apesar da mudança repentina e forçada de modalidade, podemos traçar alguns pontos positivos da modalidade remota. Um deles que observamos durante a prática docente foi a comodidade. Não haver a necessidade de sair de casa para dar aulas, no conforto da cadeira, é, com certeza, uma vantagem excelente. Não importa como está o clima, o trânsito ou o percurso até a sala de aula - o que pode implicar também na redução de atrasos. Pelo encurtamento das distâncias, abrem-se as portas aos alunos que não teriam tempo hábil de chegar até a sala de 
Reflexões sobre a prática docente e experiências de futuros professores em cursos de língua online do FIVU (Formação em Idiomas para a Vida Universitária)

Maiara Afonso de Lima

Vinícius Peretti

Fernando Silva Veloso

aula. Isso possibilita um ensino mais universal, com pessoas de outras cidades e estados, excluindo a necessidade de se morar na cidade ou nas cidades ao redor do local da sala de aula.

Foi positivo também poder usar aplicativos e ferramentas online de modo mais rápido e natural, uma vez que já estávamos todos no ambiente virtual. Com elas é possível trazer resultados instantâneos de exercícios, interagir virtualmente e disponibilizar e/ou compartilhar materiais, imagens e textos. Uma das ferramentas mais usadas foi a plataforma Learning Apps. Ela permite a criação de exercícios didáticos online, basta escolher o modelo, colocar o enunciado e preencher os campos desejados. É possível tanto enviar o link do exercícios aos alunos, como resolver junto com eles por meio de compartilhamento de tela. $\mathrm{Na}$ imagem 4 é possível ver um exercício de múltipla escolha sobre o gentílico italiano da França:

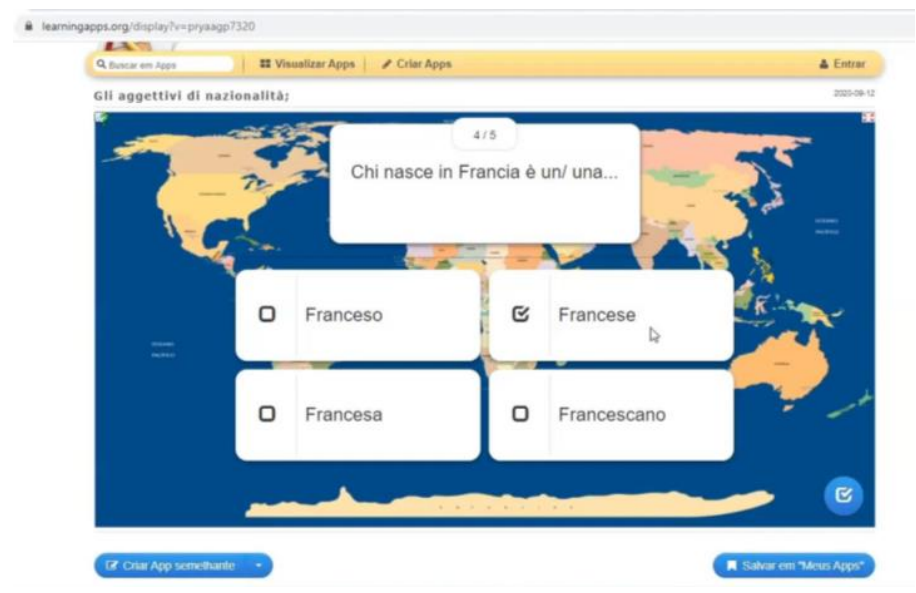

Imagem 4: exercício realizado na plataforma Learning Apps

Outra plataforma utilizada durante as aulas, até com certa regularidade, foi o Mentimeter. Com ele, torna-se possível interagir virtualmente com os alunos através de quizzes e votações em tempo real. Da mesma maneira que o Learning Apps, o 
Reflexões sobre a prática docente e experiências de futuros professores em cursos de língua online do FIVU

(Formação em Idiomas para a Vida Universitária)

Maiara Afonso de Lima

Vinícius Peretti

Fernando Silva Veloso

Mentimeter fornece uma série de modelos a serem personalizados com os dados desejados. Depois, no momento da aula, basta fornecer ao aluno o código de acesso do exercício. O exercício da imagem 5 , usado durante a aula sobre a vida universitária italiana, mostra as respostas contabilizadas de uma das perguntas:

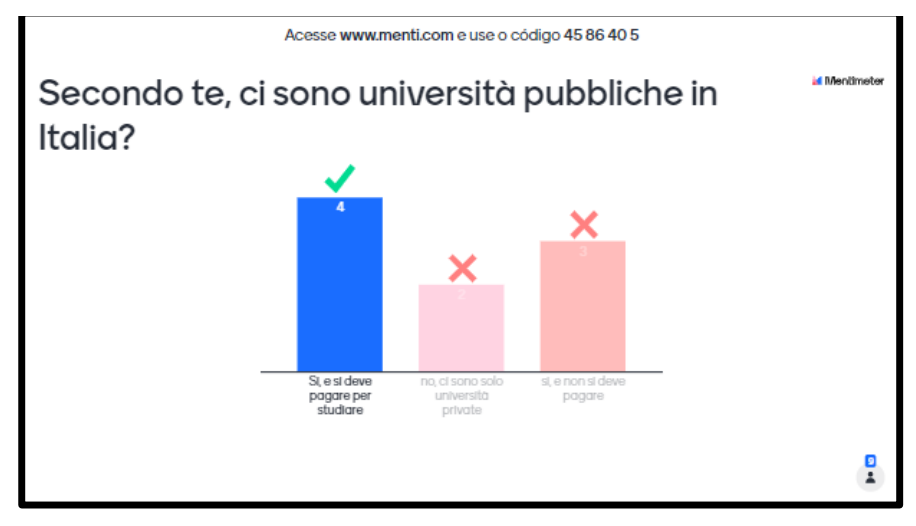

Imagem 5: exercício realizado na plataforma Mentimeter

Existe um programa chamado Epic Pen, em que é possível desenhar na tela do computador por cima de outras aplicações. Com ele, foi possível solucionar o problema de "apontar virtualmente", de direcionar a visão dos alunos para determinados elementos dos slides, vídeos e imagens, como é possível observar na imagem 6: 


\title{
VIAGGIARE IN ITALIA: COME SPOSTARSI NEL BEL PAESE
}

\begin{abstract}
II nostro Paese è da sempre tra le destinazioni preferite dai turisti di tutto il mondo: come biasimarli? Dopotutto in Italia siamo davvero preparati su tutta la linea a cominciare dalle imponenti ed affascinanti Dolomiti fino alle acque cristalline della Puglia, passando per città culturali come Bologna e Firenze, o attraversando i meravigliosi paesaggi toscani ed umbri, l'eterna Capitale, la costiera Amalfitana e tanto altro. E il caso di dire che ceTimoarazzo uella scelta.

Viaggiare in un Paese così vario deve quindi risultare tanto piacevole quanto comodo: è per questo che conviene scegliere il giusto mezzo di trasporto prima di mettersi in viaggio.

In Italia ci sono infatti diverse possibilità che ti permettono di viaggiare su tutto il territorio nazionale, dal treno al noleggio di una macchina.
\end{abstract}

Imagem 6: uso do programa Epic Pen

Por outro lado, há também as desvantagens da modalidade remota, sendo a mais evidente a falta de contato real, a "solidão" do professor. É muito comum durante as aulas que os alunos desliguem as câmeras e passem apenas a escutar. Então, ficamos olhando para a tela, sem saber se os alunos estão prestando atenção, se estão entendendo o conteúdo ou mesmo se estão presentes do outro lado da tela. No entanto, não ter ninguém, ou poucos alunos assistindo, pode ser benéfico no sentido de deixar o professor mais à vontade, pois não há aquele peso de uma dezena de olhos acompanhando cada movimento do professor durante a aula - o que pode ajudar a diminuir o filtro afetivo em sala de aula.

Outro aspecto negativo e incontornável da modalidade remota são os eventuais problemas relacionados à própria tecnologia: conexão de internet e computador. Eles ocorrem com certa frequência, seja na forma de travamentos, desconexões repentinas, sinal instável de wi-fi, seja na forma de falhas no microfone, câmera e dificuldade de acesso a arquivos ou às plataformas usadas durante a aula. Esses problemas são dificilmente prevenidos e exigem muitos recursos financeiros para investir em hardware e em uma boa conexão de internet, 
Reflexões sobre a prática docente e experiências de futuros professores em cursos de língua online do FIVU

(Formação em Idiomas para a Vida Universitária)

Maiara Afonso de Lima

Vinícius Peretti

Fernando Silva Veloso

mas mesmo assim não garantem estabilidade total.

Embora o contato reduzido tenha sido uma barreira, além dos problemas gerados pela comunicação via internet, conseguimos formar um grupo muito colaborativo de alunos realmente interessados. Nas últimas aulas do curso todos já se sentiam confortáveis o suficiente para desenvolver várias frases em italiano e arriscar novas construções, da mesma forma que ocorre nas aulas presenciais.

\section{Considerações finais}

Acreditamos que a realização da disciplina de Prática de Docência em LE Moderna 1: Espanhol/Francês/Italiano de maneira remota e com a parceria e criação do curso online de italiano pelo FIVU foi muito proveitosa e nos possibilitou aprendizados que agregam a nossa formação, não só como estudantes, mas também como profissionais da área da educação. Essa experiência nos oportunizou o nosso primeiro contato como professores de ensino a distância, fomentando a nossa bagagem e possibilitando a troca com os demais colegas da disciplina.

Além de aprimorar nossas habilidades na produção de materiais didáticos, também foi possível entender quais são algumas das adaptações necessárias quando pensamos numa sala de aula virtual, tanto na criação das atividades e conteúdos quanto na hora de colocar a aula em prática.

Vale pontuar aqui que nós ainda somos professores de LE em formação, por isso, o contato com profissionais mais experientes e o acompanhamento da coordenadora, que nos dava feedbacks depois de cada aula, foi muito valioso para o nosso crescimento e para entendermos quais aspectos poderiam ser melhorados nas nossas aulas. Da mesma forma, a criação de expectativas, o nervosismo e a 
Reflexões sobre a prática docente e experiências de futuros professores em cursos de língua online do FIVU

(Formação em Idiomas para a Vida Universitária)

Maiara Afonso de Lima

Vinícius Peretti

Fernando Silva Veloso

falta de habilidade, normais pela nossa pouca experiência, representaram desafios para nós. E mesmo tendo consciência e conhecimento sobre as metodologias de ensino que consideramos mais eficazes, e da teoria do que seria o ideal de se fazer em sala, nem sempre foi possível fazer exatamente o que havíamos planejado, em alguns momentos por conta de uma participação dos alunos diferente da esperada, em outros por descobrirmos na hora da execução que uma atividade não funcionava tão bem como havíamos imaginado.

Essa também foi nossa primeira experiência com a aplicação de um curso de italiano para fins específicos. Mesmo que nós já tivéssemos experiência com o ensino de italiano, como professores bolsistas do Centro de Línguas da UFPR (CELIN), o foco e a proposta do curso eram completamente diferentes. Além disso, mesmo que a abordagem usada nas aulas do CELIN fosse a Abordagem por Tarefas, nós usávamos como material didático básico um livro didático comercial, ou seja, não precisávamos pensar e desenvolver os materiais a cada aula.

Ao final, fomos capazes de lidar ou mesmo contornar as dificuldades que se apresentaram pela jornada, aprendendo ao mesmo tempo que ensinando; um aprendizado que será de grande valia para a formação e para o futuro. E, ao aplicar um formulário anônimo de satisfação ao final do curso, recebemos uma resposta muito positiva dos alunos, que, embora tenham apresentado sugestões de melhoria, classificaram os resultados obtidos e as aulas de maneira positiva, pedindo, inclusive, por uma continuação das atividades do curso de italiano.

\section{Nota}

1. O CAPES PRINT é o Programa Institucional de Internacionalização da Capes, que tem o objetivo de "fomentar a construção, a implementação e a consolidação de planos estratégicos de internacionalização das instituições 
Reflexões sobre a prática docente e experiências de futuros professores em cursos de língua online do FIVU

(Formação em Idiomas para a Vida Universitária)

Maiara Afonso de Lima

Vinícius Peretti

Fernando Silva Veloso

contempladas nas áreas do conhecimento por elas priorizadas; Estimular a formação de redes de pesquisas internacionais com vistas a aprimorar a qualidade da produção acadêmica vinculadas à pós-graduação; Ampliar as ações de apoio à internacionalização na pós-graduação das instituições contempladas; Promover a mobilidade de docentes e discentes, com ênfase em doutorandos, pós-doutorandos e docentes para o exterior e do exterior para o Brasil, vinculados a programas de pós-graduação stricto sensu com cooperação internacional;”

2. O Erasmus UFPR/UNIPA Itália é uma parceria entre a UFPR e a Università degli Studi di Palermo-Itália para financiamento no Projeto "Higher education student and staff mobility between Programme and Partner Countries" pela Comissão Europeia, dentro do Programa ERASMUS. Esse projeto reforça os laços entre os pesquisadores e as instituições envolvidas e está vinculada ao programa CAPES PRINT.

3. Al fine di circoscrivere più chiaramente ciò che s’intende per microlingua, è importante analizzare lo scopo d'uso della lingua. Due medici che, in una riunione mondana, si scambiano battute ricorrendo alla microlingua della medicina solo per non essere capiti dagli altri ospiti non stanno usando microlingua, ma un gergo corporativo, cioè una varietà di lingua usata da certi gruppi, non necessariamente di bassa estrazione sociale, per comunicare tra loro senza essere compresi da non - iniziati. Lo scopo è quello di selezionare il destinatario, impedendo la comprensione ai non addetti ai lavori. (BALLARIN, 2007)

4. Por uma questão de espaço, não será possível disponibilizar, neste artigo, as UTs que foram elaboradas pelos praticantes de língua italiana vinculados ao FIVU. É possível, no entanto, consultar uma das UTs aqui discutida em nosso drive: https://drive.google.com/file/d/1tAKm45pT1mhITOkFR9xiqaVIGj6i6Bbc/view?usp=sharing

\section{Referências}

BALLARIN, E. Didattica delle microlingue. Disponível em: $<$ http://venus.unive.it/filim/materiali/accesso_gratuito/Filim_microlingue_teor ia_1.pdf $>$. Data do último acesso: 24 novembro 2020.

BALBONI, P. Didattica dellitaliano a stranieri. Roma: Bonacci editore, 1994.

JORDÃO, C. M. O ensino de línguas estrangeiras, de código a discurso. Disponível em: https://docs.ufpr.br/ marizalmeida/celem2_06/o_ensino_de_lem.pdf. Data do último acesso: 29 de novembro 2020.

PICANÇO, D. C. L.; VELOSO, F. S. O ensino de língua italiana para fins acadêmicos: reflexões sobre um projeto de extensão na UFPR. In: SOUZA, R. F.; FERREIRA DA SILVA, R. (Orgs). O italiano na esfera pública brasileira: relatos, percursos e experiências de ensino e aprendizagem. Belo Horizonte: CEFET-MG, 2019. Disponível em: <http://www.letrasitaliano.ufpr.br/wpcontent/uploads/2020/06/O-italiano-na-esfera-p $\% \mathrm{C} 3 \%$.pdf $>$. Acesso em $10 \mathrm{de}$ dezembro 2020. 
Reflexões sobre a prática docente e experiências de futuros professores em cursos de língua online do FIVU (Formação em Idiomas para a Vida Universitária)

$$
\begin{gathered}
\text { Maiara Afonso de Lima } \\
\text { Vinícius Peretti } \\
\text { Fernando Silva Veloso }
\end{gathered}
$$

XAVIER, R. P. $6^{o}$ Período: Metodologia do Ensino de Inglês. Disponível em: $<$ https://castellano.ced.ufsc.br/files/2013/09/Rosely-livro-MetodologiaEnsino.pdf $>$. Data do último acesso: 25 de novembro 2020.

WILLIS, J. A framework, for task-based learning. Harlow: Longman, 1996. 